\title{
Laparoscopic Treatment of Congenital Choledochal Cysts in Children
}

\author{
Godik $\mathbf{O}^{* 1,2}$, Prytula $\mathrm{V}^{1}$, Soroutchan $\mathrm{V}^{1}$ and Dubrovin $\mathrm{A}^{1}$ \\ ${ }^{1}$ Department of Pediatric Surgery, National medical university of 00 Bogomolets, Ukraine \\ ${ }^{2}$ Department of minimally invasive pediatric surgery, Clinic "OBERIG", Ukraine
}

Submission: February 28, 2018; Published: July 10, 2018

*Corresponding author: Godik 0, Department of Pediatric Surgery, National medical university of OoBogomolets, Ukraine, Email: ogodik@ukr.net

Keywords: Laparoscopic; Congenital; Choledochal Cysts;Pediatric surgery; Hypertension; Cystic dilatation

\section{Introduction}

A congenital choledochal cyst ( $\mathrm{CHC}$ ) is a congenital malformation of the outer biliary tracts that leads to the blockage of bile flow and jaundice. If left untreated it causes episodes of cholangitis and due to long-term biliary hypertension results in the formation of biliary cirrhosis. Prospectively chronic inflammation biliary epithelium can be the cause of a cholangiocarcinoma. Thus, a surgical treatment is needed for all patients $[1,2]$.

The first anatomical classification of a CHC was introduced by Alonso-Lej et al. [1], and later edited by Todani et al. [2,3] stating five types of a CHC [1-3]. The most common types to appear in the pediatric age are type I and IV. In type one the dilatation occurs in the common bile duct and has a fusi-form. Type IV is a combination of fusi-form choledohus dilatation and cystic dilatation of the inner bile tracts. In both these types the dilatation expands to the intra- pancreatic part up to the pancreatic duct.

A wildly excepted pathogenesis theory of the type I and IV CHC formation is the anomaly of the biliopancreatic junction, where the pancreatic duct meets with the choledochus higher than the sphincter apparatus, thus leads to a reflux of the pancreatic enzymes into the choledochus resulting in constant inflammation of the choledochus epithelium $[4,5]$.

Clinically a CHC presents with a classic triad: abdominal pain; a cyst in the right upper quadrant of the abdomen; obstructive jaundice. The surgical treatment of a choledochal cyst underlines a radical excision of the cyst and the formation of a biliodigestive anastomosis (hepaticoduadenostomy or Rouxand-Y hepaticojejunostomy). Since Farelo et al. [6] first described the laparoscopic treatment for a choledochal cyst it has been gaining more and more approval in different age groups [6]. On the other hand, its feasibility and safety remain a challenge in comparison with the open operation.

\section{Materials and Methods}

In the last 5 years we admitted to our clinics 5 patients with a CHC. The median age was 4.3 years (range 11 months- 12 years).

Three patients presented with type I CHC and two children with type IV CHC according to Todani's classification. Three patients had large cysts up to $6-8 \mathrm{~cm}$, average size of the cyst was $4.5 \mathrm{~cm}$.

Clinical presentation in two children was abdominal pain and obstructive jaundice. The other three patients experienced only abdominal pain and theInstrumental pre-op diagnosing included an ultrasound (US) and computed tomography (CT) of the abdomen and a magnetic resonance cholangiopactreatography (MRCP). Such studies gave us the ability to differentiate the type of CHC, the absence or appearance of stones in the choledochus, the length of the hepatic duct before it meets the cyst, and also localize the pancreatic duct. Blood tests were a routine procedure.

\section{Surgical Options}

Patients were positioned in the "French" position. For all the cases we used a $5 \mathrm{~mm}$ camera positioned transumbilicaly, and 4 working trocars $5 \mathrm{~mm}$ or $3 \mathrm{~mm}$ - depending on the age of the patient. After revision of the abdominal cavity and visualization of the cyst we performed a traction of the liver by placing two staysutures at the fundus of the gall bladder directed to the abdominal wall. 
Mobilization of the cyst was performed with the help, of monopolar coagulation in a circular fashion until a good visualization of the right and left lobular hepatic ducts was reached. Resection of the cyst was made by excision of the hepatic duct from the cyst with a maximal dissection of the distal part of the cyst up to the pancreas followed by an excision of the cyst and suturing the underlying space. After revising the length of the hepatic duct remnant, a biliodigestive reconstruction variant was chosen.

The Roux-en-Y jejunal loop $(40 \mathrm{~cm})$ was carried out extracorporaly through the umbilicus. In three cases we performed a cyst excision with a Roux-en-Y hepaticojejunostomy, and in two cases we performed hepaticoduodenostomy. The anastomosis was made with a $6 / 0$ absorbable material. For the back wall we used a running suture, and the front wall had interrupted suturing.

\section{Results}

All five patients underwent a laparoscopic procedure without conversion. The average time of operation was $160 \pm 25$ minutes. There were no bile leakages in the post- op period. Average hospital stay was $5 \pm 2$ days. The follow- up was 24.5 months and in all cases, it was uneventful. Post- op US and blood test studies revealed normal liver function and an absence of stone formation with no dilatation of the inner biliary tracts.

Discussion. The incidence of a CHC is variable and ads- up 1 in 100,000-150,000 live births in Western countries [7] and 1 in 13,000 individuals in Japan [4]. In $85 \%$ of cases CHC is diagnosed during the first year of life.

Clinical presentation consists of a triad of symptoms: jaundice; pain in the right upper quadrant of the abdomen; presence of an abdominal mass. In this series of patients only one child had all the symptoms of the triad. In three cases clinical presentation was abdominal pain and a cystic mass localized at the hepatic helium on US. In one case a 7-month-old patient presented with obstructive jaundice that showed as cholestasis and cholestatic hepatitis in lab testing, and thus required transcutaneous drainage of the outer bile tracts [5].

An US study is an un- invasive first line diagnosing method for CHC that gives the ability to visualize the cyst, evaluate the liver structure, investigate the presence or absence of dilatation of the inner biliary tracts. CT and MRCP are specialized diagnostic methods that not only let us detect dilatation of the outer biliary tracts but let us study the relationship between the cyst itself and other neighboring anatomical structures. In our opinion such visualization increases the efficacy of surgical treatment and lessens intra-operative complications [8].

The method of choice for a CHC should be a full excision of the cyst with a biliodigestive reconstruction. The first report of a laparoscopic approach for a CHC was presented by Farelo et al. [6] in a 6-year-old child. Using this method goes along with a number of intra- operative difficulties (limited work space, high risk of trauma of the liver helium structures, difficulty of applying a biliodigestive anastomosis). All the above increases the number of post-op complications. Also, it is still controversial weather or not to use a hepaticoduodenostomy as a variant of biliodigestive reconstruction $[9,10]$.

A Roux-en-Y hepaticojejunostomy is a method of choice for most surgeons. Never the less hepaticoduodenostomy is a more preferable method of reconstruction as it is more physiologic and causes fewer complications in the post- op period.

In our short statement we would like to discuss the anatomical opportunities for performing a Roux-en-Y hepaticojejunostomy or a hepaticoduodenostomy.

The criteria for choosing to perform a hepaticoduodenostomy were: cyst size less than $3 \mathrm{~cm}$, localization of the cyst in the distal part of the choledochus; length of the remnant of the hepatic duct after cyst excision not less than $1 \mathrm{~cm}$ and its distance to the duodenum not more than $1.5 \mathrm{~cm}$ after its mobilization. In other cases, the biliodigestive reconstruction was performed by a Rouxen-Y hepaticojejunostomy.

In the lower age group 11-15months where the diameter of the hepatic duct was less than $5 \mathrm{~mm}$ to prevent stenosis of anastomosis we formed the biliodigestive anastomosis after a longitudinal transection of the front wall of the hepatic duct remnant. Thus, gave us the ability to perform an anastomosis with a diameter of $10-12 \mathrm{~mm}$.

When evaluating the duration of operative time, we stated that it took us $65 \pm 14$ less to perform hepaticoduodenostomy then a Roux-en-Y hepaticojejunostomy in the post-op period we stated an early recovery of the peristalsis and passage of intestinal contaminant. On the other hand, we didn't see a drastic difference in the post- op hospital stay between the two types of biliodigestive reconstruction.

In the follow- up period none of the children had symptoms of cholangitis or any other complications.

Our experience verifies the ability of treating a $\mathrm{CHC}$ with the laparoscopic approach even for different types of biliodigestive reconstruction. The offered methods of biliodigestive reconstruction with a Roux-en-Y hepaticojejunostomy or a hepaticoduodenostomy didn't show a reliable difference in the post- op period and the complications. On the other hand,a decree in the time of operation when performing a hepaticoduodenostomy is an important criterion when performing some laparoscopic procedures. In result this minimizes the influence of $\mathrm{CO} 2$ when undergoing a laparoscopic operation especially in small children.

\section{Conclusion}

Laparoscopic resection of $\mathrm{CHC}$ in children is an excellent treatment option и and can be the method of choice. Selecting the type of reconstruction of the bile system weather to perform a Roux-en-Y hepatico- jejunostomy or a direct hepatico- 
duodenostomy depends on the size and localization of the cyst, and also the length of the bile duct after resection.

\section{References}

1. Alonso LF, Revor WB , Pessagno DJ (1959) Congenital choledochal cyst with a report of 2, and an analysis of 94 cases. Int Abstr Surg 108(1): 1-30.

2. Todani T, Watanabe Y, Toki A, Hara H (2002) Hilar duct carcinoma developed after cyst excision followed by hepaticoduodenostomy. In: Koyanagi Y \& Aoki T (Eds) Pancreaticobiliary maljunction. Igaku tosho shuppan, Tokyo, Japan, pp. 17-21.

3. Todani T, Watanabe Y, Narusue M, Tabuchi K, Okajima K (1977) Congenital bile duct cysts: classification, operative procedures, and review of thirty-seven cases including cancer arising from choledochal cyst. Am J Surg 134(2): 26-29.

4. Sato M, Ishida H, Konno K, Naganuma H, Ishida J, et al. (2001) Choledochal cyst due to anomalous pancreatobiliary junction in the adult: sonographic findings. Abdom Imaging 26(4): 395-400.
5. Park SW, Koh H, Oh JT, Han SJ, Kim S, et al. (2014) Relationship between anomalous pancreaticobiliary ductal union and pathologic inflammation of bile duct in choledochal cyst. Pediatr Gastroenterol Hepatol Nutr 17(3): 170-177.

6. Farello GA, Cerofolini A, Rebonato M, Bergamaschi G, Ferrari C, et al. (1995) Congenital choledochal cyst: video-guided laparoscopic treatment. Surg Laparosc Endosc 5(5): 354-358.

7. Hung MH, Lin LH, Chen DF, Huang CS, et al. (2011) Choledochal cysts in infants and children: experiences over a 20 -year period at a single institution. Eur J Pediatr 170(9): 1179-1185.

8. Lee HK, Park SJ, Yi BH, Lee AL, Moon JH, et al. (2009) Imaging features of adult choledochal cysts: a pictorial review. Korean J Radiol 10(1): 71-80.

9. Diao M, Li L, Cheng W (2013) Role of laparoscopy in treatment of choledochal cysts in children. Pediatr Surg Int 29(4): 317-326.

10. Qiao G, Li L, Li S, Tang S, Wang B, et al. (2015) Laparoscopic cyst excision and Roux-Y hepaticojejunostomy for children with choledochal cysts in China: a multicenter study. Surg Endosc 29(1): 140-144.

\section{Your next submission with Juniper Publishers will reach you the below assets}

- Quality Editorial service

- Swift Peer Review

- Reprints availability

- E-prints Service

- Manuscript Podcast for convenient understanding

- Global attainment for your research

- Manuscript accessibility in different formats

( Pdf, E-pub, Full Text, Audio)

- Unceasing customer service

Track the below URL for one-step submission https://juniperpublishers.com/online-submission.php 